\title{
Autonomous Vehicles Technological Trends
}

\author{
Edgar Talavera ${ }^{1, *,+(\mathbb{D}, \text { Alberto Díaz-Álvarez }}{ }^{2,+} \mathbb{C}$, José Eugenio Naranjo ${ }^{3,+}+\mathbb{C}$ and Cristina Olaverri-Monreal ${ }^{4,+}+\mathbb{C}$ \\ 1 Escuela Técnica Superior de Ingeniería de Sistemas Informáticos, Universidad Politécnica de Madrid, \\ 28031 Madrid, Spain \\ 2 Department of Artificial Intelligence, Universidad Politécnica de Madrid, 28031 Madrid, Spain; \\ alberto.diaz@upm.es \\ 3 INSIA, Universidad Politécnica de Madrid, 28031 Madrid, Spain; joseeugenio.naranjo@upm.es \\ 4 Chair ITS-Sustainable Transport Logistics 4.0, Johannes Kepler University, 4040 Linz, Austria; \\ cristina.olaverri-monreal@jku.at \\ * Correspondence: e.talavera@upm.es; Tel.: +34-910-673-592 \\ + All authors contributed equally to this work.
}

check for updates

Citation: Talavera, E.; Díaz-Álvarez, A.; Naranjo, J.E.; Olaverri-Monreal, C. Autonomous Vehicles Technological Trends. Electronics 2021, 10, 1207. https://doi.org/10.3390

/electronics10101207

Received: 28 April 2021

Accepted: 17 May 2021

Published: 19 May 2021

Publisher's Note: MDPI stays neutral with regard to jurisdictional claims in published maps and institutional affiliations.

Copyright: (C) 2021 by the authors. Licensee MDPI, Basel, Switzerland. This article is an open access article distributed under the terms and conditions of the Creative Commons Attribution (CC BY) license (https:// creativecommons.org/licenses/by/ $4.0 /)$.

\section{Introduction}

One of the technologies widely considered to be the most promising for reducing a number of traffic-related problems, including traffic jams, safety within and outside of cities, among others, is the autonomous vehicle [1]. Currently, the autonomous vehicle is undergoing one of the most active and promising moments in recent years. Areas as diverse as Artificial Intelligence, laser sensors, cameras, radar, communications, and even detection and improvement of driver behavior are being developed collectively to improve driving, both in terms of safety and pollution reduction.

Researchers and practitioners continue to improve their knowledge in this field. There are a number of reasons for this, including our inability to say today that transportation is truly autonomous, in spite of industry investments in the development of these vehicles and academic development of technologies.

The Society of Automotive Engineers (SAE) defines five levels of automation [2] and, regardless of whether or not one agrees with this classification, the fact is that we can use it to figure out where we stand: between levels 2 (partially automated vehicles, in which the vehicle assists in driving behaviours like controlling speed and steering) and 3 (conditional automation, where "autonomy" is the concept of vehicles being able to drive themselves, but only in ideal conditions or under somewhat restrictive conditions). Levels 4 and 5 where true autonomy can be found-fully autonomous vehicles that are able to make decisions and react without human assistance-are still some ways off; however, we are on the right track.

The technologies required for these vehicles cover a large number of aspects to be investigated, distributed along tasks ranging from lower to higher levels of abstraction: perception of the environment, analysis of the information obtained, intra- and intervehicular communication, planning and decision making, action and execution of plans, and a long etcetera. Due to all these technologies, in the end, it eventually involves the inclusion of a multitude of sensors and equipment that must take into account both the economic aspects and their impact on safety.

The objective of this Special Issue is to provide the academic and industry audience with a state-of-the-art overview of the art technologies and research that support these and other aspects of autonomous driving. The contributions that make up this Special Issue have been selected both for their impact and for the key challenges they address.

\section{The Present Issue}

This Special Issue consists of thirty-one articles covering different aspects of autonomous vehicles, from those related to behavioral automation, such as trajectory prediction with obstacle avoidance, different perception and data fusion strategies, perceived 
environment analysis or the development of new ADAS [3], such as transition, to those related to the software/hardware in charge of enhancing and facilitating such automation, such as the re-architecture of embedded systems, inter- and intra-vehicular communication or new concepts of powetrain transmission ECU. All this in different domains such as, for example, urban or agricultural, not limited to only autonomous road vehicles, i.e., also including unmanned aerial vehicles (UAV).

Much of the existing research is based on Artificial Intelligence. It is not a coincidence since artificial intelligence has invaded practically all fields of engineering research in the last decade, particularly since the rise of deep learning. Some of the techniques presented in this issue include metaheuristics $[4,5]$ for improving aspects of control, artificial neural networks for perception [6,7], applications in specific environments such as traffic circles [7] or intersections [8] and prediction [9-11], and driving behavior modelling [12-14].

Furthermore, it should be mentioned that metaheuristics application area is not only limited to software for control improvement $[4,15]$, but also a way to enhance its optimization is to apply it directly on hardware, in this case by means of FPGAs [5] or even the development of SRAM hardware specifically designed for the use of AI systems [16]. One of the particularities of machine learning systems is that they facilitate the integration of all these technologies, allowing to merge different sources together, providing much more robust and efficient systems [10,17].

A large part of the improvements in autonomous coduction is due to the evolution of sensors that have been gradually improving. Although sensors alone provide great results using traditional SLAM algorithms [18], combining technologies from the field of deep learning [19] can offer a different approach. However, other approaches focus on optimizations of the sensors themselves to specialize in obstacle avoidance [20]. There are even studies [21] that seek to explain why sensors do not copy human anatomy. However, in order for the sensors to perform correctly, it is of vital importance to ensure that they are properly calibrated [22].

ITS has also placed a strong emphasis on communications between and within vehicles. Currently, vehicular communications are a developing area with a multitude of application possibilities, but they still have a long way to go in order to solve the security and infrastructure problems presented. In spite of this, one of the issues of greatest concern in cooperative systems is to guarantee the security of communications, where in [23], we can find an analysis of the risks.

As a result, more and more technologies are appearing that try to alleviate these deficiencies. In this Special Issue, we take a look at aspects such as collaborative trajectory prediction [10], cut-in-and-out maneuvers [24,25] and improved communications through unmanned aerial vehicles (UAVs) [26] from a simulation point of view, as well as in real world environments.

One of the aspects that is becoming increasingly important is energy efficiency. With it come different approaches, from the design and development of better power supplies [27], to the improvement of batteries for electric vehicles [28].

We also cover in this Special Issue the field of conditional automation describing a variety of concerns that are associated with the take over request process [29]. The article provides theoretical foundations on implemented designs, and reports on concrete examples that are targeted towards designers and the general public. Moreover, it compiles guidelines and standards related to automation in driving and highlights the research gaps that need to be addressed in future research, discussing also approaches and limitations and providing conclusions.

Even though the ITS field is heavily dominated by research examining typical automotive behavior (e.g., family vehicles) in typical driving environments (e.g., urban), the field is far more diverse than that. Various vehicle optimization areas such as aerial $[26,30]$, robot hydraulic system improvements [31], underwater [32], and agricultural [33] vehicles are explored in this issue. 


\section{Conclusions and Future Research Directions}

In order to improve our quality of life and prevent environmental degradation, we must implement continuous improvement measures. Both private enterprise and government agencies are investing in autonomous vehicle research. Several challenges remain to be studied in the increasingly complex levels of autonomous driving, which may delay the end of the investment trend in the short term.

We take this opportunity to thank all authors for contributing papers to the Special Issue. The field of autonomous vehicles and ITS-related technology continues to advance with astonishing speed, and we hope, with this Special Issue, to contribute to the body of research in the field of new technologies for automated driving.

Acknowledgments: We would like to thank all researchers who contributed to this Special Issue, as well as the reviewers who helped with the assessment and improvement of each contribution. We would like to add our thanks to the editorial board of Electronics for inviting us to edit this Special Issue. We also want to thank the Electronics Editorial Office colleagues who have diligently adhered to a rigorous peer review process and timely publication. This work was supported by the Comunidad de Madrid under Convenio Plurianual with the Universidad Politécnica de Madrid in the actuation line of Programa de Excelencia para el Profesorado Universitario. It was also supported by the Austrian Ministry for Climate Action, Environment, Energy, Mobility, Innovation and Technology (BMK) Endowed Professorship for Sustainable Transport Logistics 4.0.

Conflicts of Interest: The authors declare no conflict of interest.

\section{References}

1. Olaverri-Monreal, C. Intelligent technologies for mobility in smart cities. Hiradtech. J. 2016, 71, 29-34.

2. On-Road Automated Driving (ORAD) Committee. Taxonomy and Definitions for Terms Related to Driving Automation Systems for On-Road Motor Vehicles. 2021. Available online: https:/ / saemobilus.sae.org/content/j3016_202104 (accessed on 8 April 2021). [CrossRef]

3. Park, J.; Choi, B.W. Design and Implementation Procedure for an Advanced Driver Assistance System Based on an Open Source AUTOSAR. Electronics 2019, 8, 1025. [CrossRef]

4. Naranjo, J.E.; Serradilla, F.; Nashashibi, F. Speed Control Optimization for Autonomous Vehicles with Metaheuristics. Electronics 2020, 9, 551. [CrossRef]

5. Huang, H.C.; Tao, C.W.; Chuang, C.C.; Xu, J.J. FPGA-based mechatronic design and real-time fuzzy control with computational intelligence optimization for Omni-Mecanum-wheeled autonomous vehicles. Electronics 2019, 8, 1328. [CrossRef]

6. Guo, Z.; Huang, Y.; Hu, X.; Wei, H.; Zhao, B. A Survey on Deep Learning Based Approaches for Scene Understanding in Autonomous Driving. Electronics 2021, 10, 471. [CrossRef]

7. García Cuenca, L.; Puertas, E.; Fernandez Andrés, J.; Aliane, N. Autonomous Driving in Roundabout Maneuvers Using Reinforcement Learning with Q-Learning. Electronics 2019, 8, 1536. [CrossRef]

8. Narksri, P.; Takeuchi, E.; Ninomiya, Y.; Takeda, K. Deadlock-Free Planner for Occluded Intersections Using Estimated Visibility of Hidden Vehicles. Electronics 2021, 10, 411. [CrossRef]

9. Zhao, B.; Huang, Y.; Wei, H.; Hu, X. Ego-Motion Estimation Using Recurrent Convolutional Neural Networks through Optical Flow Learning. Electronics 2021, 10, 222. [CrossRef]

10. Choi, D.; Yim, J.; Baek, M.; Lee, S. Machine Learning-Based Vehicle Trajectory Prediction Using V2V Communications and On-Board Sensors. Electronics 2021, 10, 420. [CrossRef]

11. Ahmad, E.; Iqbal, J.; Arshad Khan, M.; Liang, W.; Youn, I. Predictive Control Using Active Aerodynamic Surfaces to Improve Ride Quality of a Vehicle. Electronics 2020, 9, 1463. [CrossRef]

12. Tsai, W.C.; Lai, J.S.; Chen, K.C.; Shivanna, V.M.; Guo, J.I. A lightweight motional object behavior prediction system harnessing deep learning technology for embedded adas applications. Electronics 2021, 10, 692. [CrossRef]

13. Cui, G.; Wang, S.; Wang, Y.; Liu, Z.; Yuan, Y.; Wang, Q. Preceding Vehicle Detection Using Faster R-CNN Based on Speed Classification Random Anchor and Q-Square Penalty Coefficient. Electronics 2019, 8, 1024. [CrossRef]

14. Kim, H.; Kim, W.; Kim, J.; Lee, S.J.; Yoon, D.; Jo, J. A Study on Re-Engagement and Stabilization Time on Take-Over Transition in a Highly Automated Driving System. Electronics 2021, 10, 344. [CrossRef]

15. Matute-Peaspan, J.A.; Marcano, M.; Diaz, S.; Zubizarreta, A.; Perez, J. Lateral-Acceleration-Based Vehicle-Models-Blending for Automated Driving Controllers. Electronics 2020, 9, 1674. [CrossRef]

16. Kim, Y.; Patel, S.; Kim, H.; Yadav, N.; Choi, K.K. Ultra-Low Power and High-Throughput SRAM Design to Enhance AI Computing Ability in Autonomous Vehicles. Electronics 2021, 10, 256. [CrossRef]

17. San Martín, J.; Cortés, A.; Zamora-Cadenas, L.; Svensson, B.J. Precise Positioning of Autonomous Vehicles Combining UWB Ranging Estimations with On-Board Sensors. Electronics 2020, 9, 1238 [CrossRef] 
18. Ren, R.; Fu, H.; Wu, M. Large-Scale Outdoor SLAM Based on 2D Lidar. Electronics 2019, 8, 613. [CrossRef]

19. Oh, M.; Cha, B.; Bae, I.; Choi, G.; Lim, Y. An Urban Autodriving Algorithm Based on a Sensor-Weighted Integration Field with Deep Learning. Electronics 2020, 9, 158. [CrossRef]

20. Masood, K.; Molfino, R.; Zoppi, M. Simulated Sensor Based Strategies for Obstacle Avoidance Using Velocity Profiling for Autonomous Vehicle FURBOT. Electronics 2020, 9, 833. [CrossRef]

21. Dickmanns, E.D. May a Pair of 'Eyes' Be Optimal for Vehicles Too? Electronics 2020, 9, 759. [CrossRef]

22. Lei, W.; Xu, M.; Hou, F.; Jiang, W.; Wang, C.; Zhao, Y.; Xu, T.; Li, Y.; Zhao, Y.; Li, W. Calibration Venus: An Interactive Camera Calibration Method Based on Search Algorithm and Pose Decomposition. Electronics 2020, 9, 2170. [CrossRef]

23. Luo, F.; Hou, S.; Zhang, X.; Yang, Z.; Pan, W. Security Risk Analysis Approach for Safety-Critical Systems of Connected Vehicles. Electronics 2020, 9, 1242. [CrossRef]

24. Lee, G.; Ha, S.; Jung, J.I. Integrating Driving Hardware-in-the-Loop Simulator with Large-Scale VANET Simulator for Evaluation of Cooperative Eco-Driving System. Electronics 2020, 9, 1645. [CrossRef]

25. Schinkel, W.; van der Sande, T.; Nijmeijer, H. State Estimation for Cooperative Lateral Vehicle Following Using Vehicle-to-Vehicle Communication. Electronics 2021, 10, 651. [CrossRef]

26. Jobaer, S.; Zhang, Y.; Iqbal Hussain, M.A.; Ahmed, F. UAV-assisted hybrid scheme for urban road safety based on VANETs. Electronics 2020, 9, 1499. [CrossRef]

27. Biba, D.R.; Ancuti, M.C.; Ianovici, A.; Sorandaru, C.; Musuroi, S. Power Supply Platform and Functional Safety Concept Proposals for a Powertrain Transmission Electronic Control Unit. Electronics 2020, 9, 1580. [CrossRef]

28. Han, K.; Nguyen, T.W.; Nam, K. Battery Energy Management of Autonomous Electric Vehicles Using Computationally Inexpensive Model Predictive Control. Electronics 2020, 9, 1277. [CrossRef]

29. Morales-Alvarez, W.; Sipele, O.; Léberon, R.; Tadjine, H.H.; Olaverri-Monreal, C. Automated Driving: A Literature Review of the Take over Request in Conditional Automation. Electronics 2020, 9, 2087. [CrossRef]

30. Guo, A.; Zhou, Z.; Zhu, X.; Zhao, X.; Ding, Y. Automatic control and model verification for a small aileron-less hand-launched solar-powered unmanned aerial vehicle. Electronics 2020, 9, 364. [CrossRef]

31. Masood, K.; Dauptain, X.; Zoppi, M.; Molfino, R. Hydraulic Pressure-Flow Rate Control of a Pallet Handling Robot for an Autonomous Freight Delivery Vehicle. Electronics 2020, 9, 1370. [CrossRef]

32. Wang, X.; Sun, Y.; Wan, L.; Bian, H.; Ran, X. Design and Reliability Analysis of a Tunnel-Detection AUV Based on a Heterogeneous Dual CPU Hot Redundancy System. Electronics 2021, 10, 22. [CrossRef]

33. Pérez, S.S.; López, J.M.G.; Jimenez Betancourt, R.O.; Villalvazo Laureano, E.; Solís, J.E.M.; Sánchez Cervantes, M.G.; Ochoa Guzmán, V.J. A Low-Cost Platform for Modeling and Controlling the Yaw Dynamics of an Agricultural Tractor to Gain Autonomy. Electronics 2020, 9, 1826. [CrossRef] 